\title{
IMPACT: an implicit time integration scheme for chemical species and families
}

\author{
G. D. Carver ${ }^{1}$, P. A. Stott ${ }^{2}$ \\ ${ }^{1}$ Centre for Atmospheric Science, Chemistry Department, Cambridge University, Lensfield Road, Cambridge, CB2 1EW, UK \\ ${ }^{2}$ Meteorology Department, Edinburgh University, Kings Buildings, Mayfield Road, Edinburgh, EH9 3JZ, UK*
}

Received: 16 December 1998 / Revised: 19 May 1999 / Accepted: 21 May 1999

\begin{abstract}
The implicit time integration scheme of Stott and Harwood (1993) was proposed as an efficient scheme for use in three-dimensional chemical models of the atmosphere. The scheme was designed for chemistry schemes using 'chemical families', in which species with short lifetimes are grouped into longer-lived families. Further study with more complex chemistry, more species and reactions showed the scheme to be non-convergent and unstable under certain conditions; particularly for the perturbed chemical scenarios of polar stratospheric winters. In this work the scheme has been improved by revising the treatment of families and the convergence properties of the scheme. The new scheme has been named IMPACT (IMPlicit Algorithm for Chemical Time-stepping). It remains easy to implement and produces simulations that compare well with integrations using more accurate higher order schemes.
\end{abstract}

Key words: Atmospheric composition and structure (middle atmosphere - composition and chemistry; lioposphere - composition and chemistry; instruments and techniques)

\section{Introduction}

Atmospheric chemistry is now widely used in threedimensional global and regional atmospheric models for studies of stratospheric and tropospheric chemistry (e.g. Rose and Brasseur, 1989; Chipperfield et al., 1996; Law et al., 1998) and air quality (e.g. Dabdub and Seinfeld, 1995). The computational cost of such models can be

Correspondence to: G. D. Carver

E-mail: glenn@atm.ch.cam.ac.uk

*Present address: UK Meteorological Office, Bracknell,

Berkshire, UK very demanding. For example, current work on stratospheric polar ozone depletion makes use of global atmospheric models with a detailed description of stratospheric chemistry; perhaps 30 or more species and several hundred reactions as well as a treatment of heterogeneous chemical processes. The chemical species used vary on a very wide range of time scales. Many species can vary much faster than typical time steps used in the atmospheric model. This results in a stiff system of ordinary differential equations that must be solved at each time step. However, numerical methods to solve such equations can be very costly and instead accuracy is often sacrificed for computational speed and approximations are introduced.

One way of reducing the computational cost is to reduce the stiffness of the problem by assuming some species are in photochemical equilibrium, often called steady-state, so that these species do not need to be integrated in time. Also, chemical species can be grouped into 'families' (Austin, 1991) where like species, for example odd oxygen species, are parameterised in terms of a single chemical tracer.

Computational cost can also be reduced by suitable choice of the time integration method or 'ODE solver'. These methods can be categorized into explicit and implicit methods (Mesinger and Arakawa, 1976). In explicit methods, the tendencies of the species are computed from known values at previous times. Whilst these methods are generally computationally cheap and easy to implement, the time step must satisfy a stability criteria. Implicit methods compute the tendencies of species based not only on previous values but on future values not yet known. Although no stability criteria is usually imposed on the time step for these methods, they are computationally more costly because matrix inversions and step size control are often used. A large number of explicit and implicit schemes have been investigated and reviewed (e.g. Radhakrishnan, 1991; Verwer and Simpson, 1995; Hairer and Wanner, 1996; Sandu et al., 1997a, b). Backward differentiation formulae (BDF) methods developed by Gear (1971) pro- 
vide accurate solutions to stiff problems and are often used for benchmarking other integrations schemes. However many authors have sought ways to take advantage of the nature of the equations resulting from atmospheric chemistry schemes and the relatively low accurately requirements. For example, Jacobson and Turco (1994) and Jacobson (1995) have adapted a Gear (1971) method to make it more efficient on vector computer architectures by making use of vectorized sparse matrix methods. Other authors have sought to introduce approximations to either reduce or avoid the computation involved in matrix inversions or operations associated with implicit methods (e.g. Ramaroson et al., 1992; Suhre and Rosset, 1994; Sandilands and McConnell, 1997).

Stott and Harwood (1993) proposed a fixed time step implicit scheme which avoided the use of a matrix inversion in solving the implicit equations. It was similar to the approach used by Sillman (1991) for tropospheric chemistry. The scheme was tested in a global circulation model (GCM) and found to be as accurate and cheaper than an explicit scheme using short time steps. A set of chemical families and species were used that were typical of a basic stratospheric chemistry scheme (Lary et al., 1994). However, when used with a more comprehensive stratospheric chemistry scheme, in particular when heterogeneous chemistry on polar stratospheric clouds was introduced, some problems occurred. The scheme was found not to converge to a solution and even become unstable in certain circumstances. Also, the treatment of chemical families in this integration scheme was not discussed by Stott and Harwood (1993) and was subsequently found to need modifications. In this work we describe the improvements made to the original scheme of Stott and Harwood (1993, hereafter referred to as SH93) to improve its convergence properties and describe how the chemical families should be implemented. The new scheme is called IMPACT and remains easy to implement and computationally economical.

In the next section the formulation of the scheme is developed. In the subsequent section some results from test integrations of the scheme are presented and discussed, before a summary is presented.

\section{Formulation of IMPACT}

In this section the formulation of the scheme proposed by SH93 is described and the enhancements that have been included in the scheme to produce IMPACT are detailed. Some duplication with SH93 is necessary for completeness. The reader is referred to $\mathrm{SH} 93$ for a complete discussion of the properties of the scheme.

\subsection{The original scheme}

For a single species, $y^{i}$, an equation of the form

$\frac{\mathrm{d}}{\mathrm{d} t} y^{i}=P^{i}-L^{i} y^{i}$ must be integrated. $P$ represents the sum of the production terms and $L$ represents the sum of the loss terms. Note that if $y$ self-reacts, another term $L^{\prime} y^{2}$ should be included. However, this is omitted for clarity here. A chemical scheme using $N$ species or families is represented by the following set of ordinary differential equations

$\frac{\mathrm{d} \boldsymbol{y}}{\mathrm{d} t}=\boldsymbol{f}(\boldsymbol{y})$,

where $\boldsymbol{y}$ is the species vector and $\boldsymbol{f}$ is also a vector and represents the sum of the production and loss terms (i.e. the RHS of Eq. 1). The implicit Euler backwards scheme applied to Eq. (2) is

$\left(\boldsymbol{y}_{n+1}-\boldsymbol{y}_{n}\right) / \Delta t=\boldsymbol{f}\left(\boldsymbol{y}_{n+1}\right)$,

which is unconditionally stable and first order accurate, as is well known (see for example Mesinger and Arakawa, 1976).

The method proposed in SH93 was to carry out a Newton-Raphson iteration to solve Eq. (3) which is given by

$$
\begin{aligned}
\boldsymbol{y}_{n+1}^{(m+1)}= & \boldsymbol{y}_{n+1}^{(m)}+\left(\mathbf{I}-\Delta t \mathbf{J}_{n+1}^{(m)}\right)^{-1} \\
& \left(-\boldsymbol{y}_{n+1}^{(m)}+\Delta t \boldsymbol{f}\left(\boldsymbol{y}_{n+1}^{(m)}\right)+\boldsymbol{y}_{n}\right),
\end{aligned}
$$

where the superscript $(m)$ denotes the value at the $m$ th iteration, $\mathbf{I}$ is the identity matrix and $\mathbf{J}=\partial \boldsymbol{f} / \partial \boldsymbol{y}$ is known as the Jacobian matrix of derivatives. The initial value for the iteration $\boldsymbol{y}_{n+1}^{(0)}$ is calculated from a linearised approximation to Eq. (3)

$\frac{\boldsymbol{y}_{n+1}^{(0)}-\boldsymbol{y}_{n}}{\Delta t}=\boldsymbol{f}\left(\boldsymbol{y}_{n}\right)+\mathbf{J}_{n}\left(\boldsymbol{y}_{n+1}^{(0)}-\boldsymbol{y}_{n}\right)$.

Equation (5) is the formula for the predictor step and Eq. (4) is the corrector step. The method proposed by SH93 achieved savings in computational cost by approximating the matrix

$\mathbf{A}=\mathbf{I}-\Delta t \mathbf{J}$,

with only its main diagonal in Eqs. (4) and (5), preventing the need for an expensive matrix inversion. The approximate matrix, $\mathbf{B}$, is defined

$$
\begin{aligned}
B_{i j} & =A_{i j} \quad \text { if } \quad i=j \\
& =0 \quad \text { otherwise . }
\end{aligned}
$$

\subsection{Chemical families}

A description of the treatment of chemical families was not included in SH93 although the method was tested using a chemistry that included the odd oxygen, nitrogen and chlorine families. The original implementation has been found to be somewhat incorrect, as explained in this section, and IMPACT incorporates a revised implementation of chemical families.

In general terms, a chemical family will consist of several species, one of which is sufficiently long-lived whilst the others are assumed to be in equilibrium with 
each other; often called 'steady-state'. For example, the $\mathrm{ClO}_{\mathrm{x}}$ family might be

$\mathrm{ClO}_{\mathrm{x}}=\mathrm{Cl}+\mathrm{ClO}+2 \mathrm{Cl}_{2} \mathrm{O}_{2}$,

where $\mathrm{Cl}$ and $\mathrm{Cl}_{2} \mathrm{O}_{2}$ are assumed to be in steady-state. The rate of change of $\mathrm{ClO}_{\mathrm{x}}$ is therefore the sum of the rate of change of its constituents.

If only the main diagonal of the Jacobian matrix $\mathbf{J}$ is retained, for a non-family species, it is clear from Eq. (1) that only the reactions representing a loss of the species are retained. However, this is not the case for families as will be shown.

For a chemical family, the retained main diagonal element of the Jacobian matrix (written as $e_{i}$ ) is the rate of change of the family tendency with itself. For example, for the reaction

$\mathrm{Cl}+\mathrm{O}_{3} \rightarrow \mathrm{ClOO}+\mathrm{O}$

the contribution to the retained Jacobian element for $\mathrm{ClO}_{\mathrm{x}}$ is

$e=-k \frac{\partial}{\partial\left[\mathrm{ClO}_{\mathrm{x}}\right]}[\mathrm{Cl}]\left[\mathrm{O}_{3}\right]$.

In order to solve this $[\mathrm{Cl}]$ is written as

$[\mathrm{Cl}]=\left([\mathrm{Cl}] /\left[\mathrm{ClO}_{\mathrm{x}}\right]\right)\left[\mathrm{ClO}_{\mathrm{x}}\right]$

and the ratio $\left([\mathrm{Cl}] /\left[\mathrm{ClO}_{\mathrm{x}}\right]\right)=R_{\mathrm{Cl}}$ is assumed to be constant with respect to a change in the $\mathrm{ClO}_{\mathrm{x}}$ family i.e.

$e=-k R_{\mathrm{Cl}}\left[\mathrm{O}_{3}\right]$.

For a reaction in which both reactants are family members (or a family member self reacts), the Jacobian element includes the family itself. e.g. for the reaction

$\mathrm{Cl}+\mathrm{Cl}_{2} \mathrm{O}_{2} \rightarrow \mathrm{Cl}_{2}+\mathrm{ClOO}$

(assuming that neither $\mathrm{Cl}_{2}$ nor $\mathrm{ClOO}$ are in the $\mathrm{ClO}_{\mathrm{x}}$ family), its contribution to the retained Jacobian term would be

$e=-4 k R_{\mathrm{Cl}} R_{\mathrm{Cl}_{2} \mathrm{O}_{2}}\left[\mathrm{ClO}_{\mathrm{x}}\right]$.

Although the ratios $R$ are assumed to be constant with respect to changes in the concentration of the family, they are not constant with respect to time. This means that for each chemical step, the ratios must be evaluated twice; first for the predictor step, Eq. (5), then again for the first Newton-Raphson corrector iteration Eq. (4). This second evaluation of the ratios is necessary because the predictor step will integrate to the next time level, so the ratios will have changed. However, since the ratios do not depend on the family concentrations, they do not need to be recalculated at each iteration of the corrector step. This is fortunate since calculating the ratios can be a computationally expensive procedure. If, as mistakenly done in the SH93 scheme, the ratios are not recalculated after the predictor step, the corrector iteration may converge to the wrong solution. This led to conservation problems in the $\mathrm{SH} 93$ scheme so that an ad hoc method of maintaining conservation of $\left[\mathrm{ClO}_{\mathrm{x}}\right]$ had to be used in the model. In IMPACT by ensuring the ratios $R$ are computed twice, both before and after the predictor step, the method is conservative and no additional steps in the model need to be included to ensure conservation.

\subsection{The predictor step}

All the reactions that have been considered have been a loss from the family and made a negative contribution to the main diagonal term in the Jacobian matrix. Since this term represents the change in tendency of the family with itself, with a family of species it is possible to get a net production into the family, resulting in a positive contribution to the retained Jacobian term. Consider the reaction

$\mathrm{Cl}+\mathrm{ClONO}_{2} \rightarrow \mathrm{Cl}_{2}+\mathrm{NO}_{3}$

To avoid dealing with species which have small concentrations and to reduce computational expense, in out stratospheric chemistry scheme $\mathrm{Cl}_{2}$ is not retained and instead assumed to form $2 \mathrm{Cl}$ immediately. The reaction then becomes

$\mathrm{Cl}+\mathrm{ClONO}_{2} \rightarrow \mathrm{Cl}+\mathrm{Cl}+\mathrm{NO}_{3}$.

The Jacobian element, $e$, for this reaction is then given by

$e=k[\mathrm{Cl}]\left[\mathrm{ClONO}_{2}\right]$,

that is, a positive contribution to the main diagonal term. During experiments to study the polar chemistry in the lower stratosphere associated with polar stratospheric cloud processing, the concentration of $\mathrm{ClONO}_{2}$ can increase such that Eq. (14) dominates the Jacobian element, $e$, for $\mathrm{ClO}_{\mathrm{x}}$ making it positive instead of negative. This results in a poor predictor step which can prevent the Newton-Raphson iteration from converging. It may also produce a negative concentration.

In IMPACT, to prevent a poor predictor step in general, the sign of the Jacobian in Eq. (5) is checked and a simple Euler forward step is used instead for the first guess if this term is positive. Although this can underestimate the concentrations during production, for example in Eq. (14), this error is remedied during the corrector iteration. As a test, for the stratospheric chemistry scheme using chemical families described later, we replaced the predictor step by an Euler forward scheme for every time step and it only resulted in at most one more corrector iteration for some time steps.

\subsection{The corrector iteration}

The predictor step, Eq. (5), may be quote a poor estimate during the morning or when photolysis switches on (i.e. when production dominates), since only the diagonal terms and therefore the loss terms in the Jacobian are included. The predictor step is worst for those species and families which have a strong diurnal variation such as $\mathrm{BrO}_{\mathrm{x}}$ and $\mathrm{OClO}$. When the scheme proposed by $\mathrm{SH} 93$ was implemented in the threedimensional chemical transport model SLIMCAT (Chipperfield et al., 1996) for a chemistry that included 
bromine species (not considered by SH93), the NewtonRaphson corrector iteration failed to converge at sunrise when $\mathrm{ClO}_{\mathrm{x}}$ was enhanced due to chemical processing on polar stratospheric clouds. Although the NewtonRaphson method has excellent local convergence properties, converging quadratically near the root (Press et al., 1992), its global convergence properties are poor and if the predictor step is too far from the final solution it may fail to converge.

Globally convergent Newton methods which overcome the problem of a poor predictor step already exist in the literature. See for example the method presented by Press et al. (1992) which uses line searching and back-tracking. However, these schemes rely on an accurate approximation to the Jacobian matrix and will not work when the Jacobian matrix is approximated only by the main diagonal as for this scheme.

Recall from the discussion in Sect. 2.2 that the main diagonal in the Jacobian matrix is dominated by loss terms (see Eq. 1) and that the original scheme does not converge when sunlight returns to photolyze the large concentrations of $\mathrm{ClONO}_{2}$. An improvement should be obtained if a better estimate of the matrix A (Eq. 6) was used in which only the production terms due to photolysis were added to the matrix $\mathbf{B}$. Since there are generally many fewer photolysis reactions than the overall number of reactions, the computational cost of doing this can be kept small. In addition, this only needs to be done when the corrector iteration does not appear to be converging.

It is not necessary to compute these new off-diagonal terms exactly. An approximation can be used which further reduces the computational cost and makes it easy to implement this addition to the scheme. The improved matrix, $C$, is found by writing $\mathbf{A}$ as

$\mathbf{A}=\mathbf{B}+\delta \mathbf{A}$

and using a binomial expansion

$$
\begin{aligned}
\mathbf{A}^{-1} & =(\mathbf{B}+\delta \mathbf{A})^{-1} \\
& =\left(\mathbf{B}\left(\mathbf{I}+\mathbf{B}^{-1} \delta \mathbf{A}\right)\right)^{-1} \\
& =\left(\mathbf{I}+\mathbf{B}^{-1} \delta \mathbf{A}\right)^{-1} \cdot \mathbf{B}^{-1} \\
& \approx\left(\mathbf{I}-\mathbf{B}^{-1} \delta \mathbf{A}+\cdots\right) \mathbf{B}^{-1} .
\end{aligned}
$$

A better approximation to $\mathbf{A}$ is therefore given by

$\mathbf{C}=\mathbf{B}^{-1}-\mathbf{B}^{-1} \delta \mathbf{A} \mathbf{B}^{-1}$.

Equation (17) is efficient because it still only requires the trivial inversion of the same matrix, $\mathbf{B}$, which only has non-zero terms on the main diagonal. Furthermore, the second term on the RHS represents a correction to the matrix that can be readily computed. Not only has the Jacobian matrix been approximated but so has its inverse.

\section{Results}

In this section, a number of tests are described to verify the IMPACT scheme and compare it with both the original SH93 scheme and a high accuracy stiff integrator. A number of runs using a model which represents a single point in the atmosphere (known as a box model) are carried out.

\subsection{Chemical model}

The IMPACT scheme is used by the ASAD atmospheric chemistry integration package (Carver et al., 1997) which allows chemistry schemes to be developed rapidly with little programming. IMPACT has been tested in a typical stratospheric chemistry scheme that might be used to study polar ozone loss and includes chlorine, bromine, nitrogen and hydrogen species. This is a more comprehensive chemistry scheme than used by SH93, who did not include the bromine species nor any heterogeneous chemistry. The following species and families are included:

\section{Chemical families}

$\mathrm{O}_{\mathrm{x}}=\mathrm{O}_{3}+\mathrm{O}\left({ }^{3} \mathrm{P}\right)+\mathrm{O}\left({ }^{1} \mathrm{D}\right)$,

$\mathrm{NO}_{\mathrm{x}}=\mathrm{NO}+\mathrm{NO}_{2}+\mathrm{NO}_{3}$,

$\mathrm{ClO}_{\mathrm{x}}=\mathrm{Cl}+\mathrm{ClO}+2 \mathrm{Cl}_{2} \mathrm{O}_{2}$,

$\mathrm{BrO}_{\mathrm{x}}=\mathrm{Br}+\mathrm{BrO}$,

Species integrated separately

$\mathrm{OClO}, \mathrm{BrCl}, \mathrm{BrONO}{ }_{2}, \mathrm{~N}_{2} \mathrm{O}, \mathrm{N}_{2} \mathrm{O}_{5}, \mathrm{HNO}_{3}, \mathrm{HO}_{2} \mathrm{NO}_{2}$, $\mathrm{HCl}, \mathrm{HOCl}, \mathrm{HBr}, \mathrm{HOBr}, \mathrm{ClONO}_{2}, \mathrm{CO}, \mathrm{CH}_{4}, \mathrm{H}_{2} \mathrm{O}_{2}$, $\mathrm{H}_{2} \mathrm{O}, \mathrm{HCHO}, \mathrm{CH}_{3} \mathrm{OOH}$,

Species assumed to be in photochemical equilibrium

$\mathrm{OH}, \mathrm{HO}_{2}, \mathrm{CH}_{3} \mathrm{O}, \mathrm{CH}_{3} \mathrm{OO}$,

Species treated as constant

$\mathrm{CO}_{2}, \mathrm{H}_{2}, \mathrm{O}_{2}$ and $\mathrm{N}_{2}$.

Those species assumed to be in photochemical equilibrium are not integrated in time. They are computed at each time step by assuming that their total chemical rate of change is zero.

Other species considered whilst developing the chemical reaction set for this model are; $\mathrm{H}, \mathrm{N}, \mathrm{ClOO}, \mathrm{Cl}_{2}$, $\mathrm{ClNO}_{2}, \mathrm{CH}_{3}, \mathrm{HCO}$ and $\mathrm{CH}_{3} \mathrm{O}$ but since these species either have short life times or exist in low concentrations they are not included in this chemistry scheme. However, where they appear as a product in a reaction, it is assumed that the species immediately forms the products from its dominant reaction. For example, if $\mathrm{N}$ appears as a product in a reaction it is replaced by NO $+\mathrm{O}\left({ }^{3} \mathrm{P}\right)$ (assuming that any $\mathrm{N}$ produced is immediately lost by reacting with $\mathrm{O}_{2}$ ). Removing species in this way 
reduces the computational cost of the model with negligible impact on the results.

There are 117 gaseous reactions and 25 photolysis reactions for which the rates are calculated by using full spherical geometry and multiple scattering as described by Lary and Pyle (1992a, b) after Meier et al. (1982), Nicolet et al. (1982) and Anderson (1983). the model includes a treatment of heterogeneous reactions on polar stratospheric clouds (PSCs) (WMO, 1991) but for these tests does not include reactions on sulfate aerosol particles.

In the next section IMPACT has been tested by comparing its performance with the VODE variable coefficient stiff ODE integrator as described in Brown et al. (1989) (available from the NETLIB Internet Software Repository, http://www.netlib.org/). Like most stiff integrators, VODE maintains the local error in the solution below user-specified relative and absolute tolerances. It is therefore used here as a benchmark. VODE takes much smaller times steps than IMPACT when chemical constituents are changing quickly whereas IMPACT has a fixed time step. It is too computationally expensive for routine use in three-dimensional atmospheric chemistry models, but can be used in a box or trajectory model to test the accuracy of more economical schemes such as IMPACT.

\subsection{Short integrations}

When the original SH93 scheme was implemented in the SLIMCAT (Chipperfield et al., 1996) transport model for the chemistry described already, it could become unstable following heterogeneous processing on polar stratospheric clouds. In this first test, the chemical species are initialised with concentrations that were found to cause the SH93 scheme to fail. The box is fixed at $62^{\circ} \mathrm{N}, 0^{\circ} \mathrm{E}, 90 \mathrm{hPa}$ (approximately $410 \mathrm{~K}$ ). There has been a PSC event and the concentration of $\mathrm{ClO}_{\mathrm{x}}$ is elevated. If the original scheme of $\mathrm{SH} 93$ is used to integrate from these initial conditions, the corrector step fails to converge during the first day due to a poor first guess from the predictor step.

For all the following tests, a 15 min time step is used for IMPACT. The time step for the VODE integrator is allowed to vary according to its default configuration. The relative tolerance for both IMPACT and VODE, which is used to determine when the solution for a particular time step has converged, is set to $10^{-5}$. The integrators also use an absolute tolerance for each species so that when a species concentration drops below its absolute tolerance it is also assumed to have converged. In these tests the absolute tolerance was set to $10^{-20}$ normalized by the total number density.

Figure 1 shows a comparison between IMPACT and VODE for some of the chlorine species; $\mathrm{ClONO}_{2}, \mathrm{HCl}$ and $\mathrm{ClO}_{\mathrm{x}}$. During the 6.5 days of the integration the $\mathrm{ClO}_{x}$ is returning to its reservoir forms of $\mathrm{ClONO}_{2}$ and $\mathrm{HCl}$. Note that the IMPACT scheme successfully completes these test case whereas the original SH93 scheme would fail. Figure 1a shows that the IMPACT
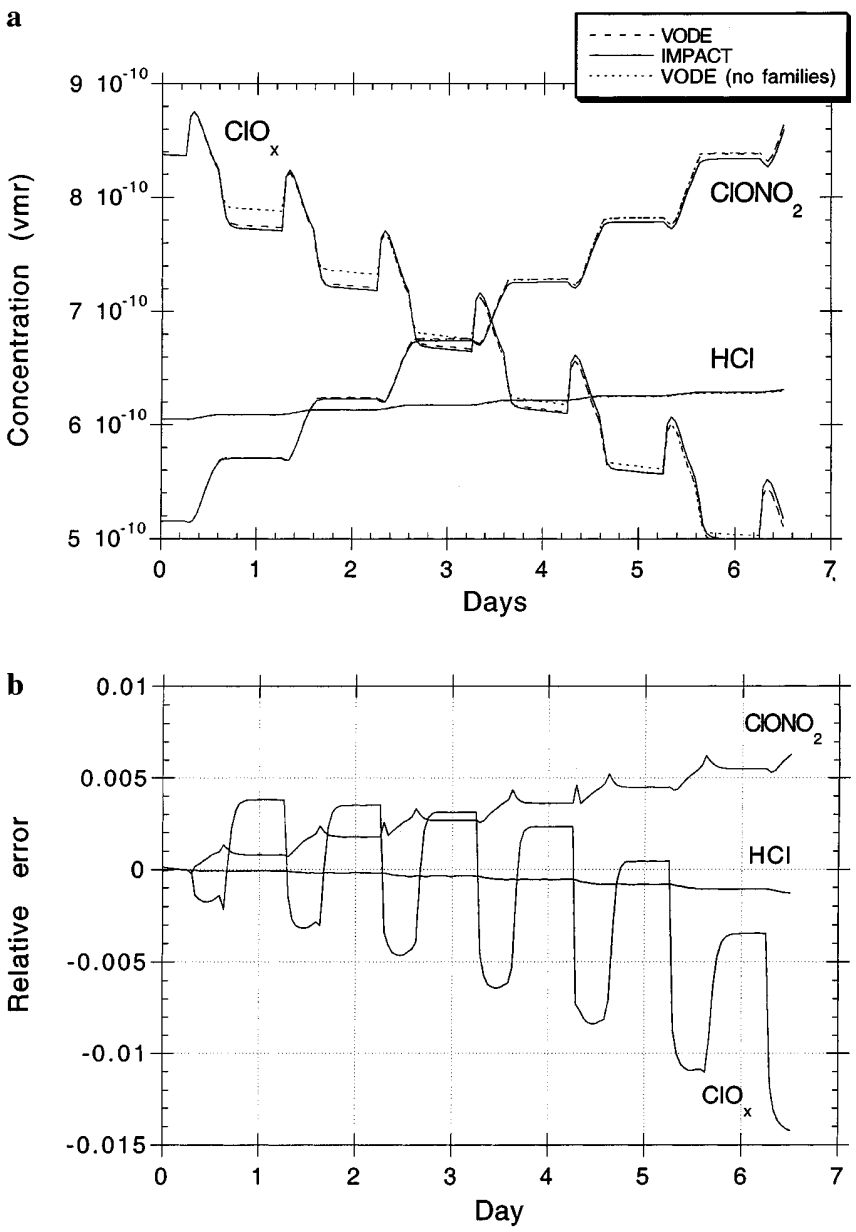

Fig. 1a, b. A comparison of the results using the IMPACT and VODE integrators for $\mathrm{ClONO}_{2}, \mathrm{HCl}$ and $\mathrm{ClO}_{\mathrm{x}}$ for the 6.5 day run. a Concentrations are in volume mixing ratio. Three curves are plotted for each species. The IMPACT integration is the solid curve. The long dashed curve is VODE integration using chemical families, whereas the dotted curve is the VODE integration in which no chemical families or steady state species are used. For $\mathrm{ClONO}_{2}$ and $\mathrm{HCl}$, both the VODE curves are coincident, whereas the two VODE curves for $\mathrm{ClO}_{x}$ show a difference during the night-time. b Relative error of these species defined as (VODE-IMPACT)/VODE, where the VODE run which includes chemical families is used

run compares very well with the more accurate solution using VODE when considering the case when VODE is used with the same chemical families and steady-state species as used in the IMPACT case. Figure $1 \mathrm{~b}$ shows that initially, IMPACT slightly underestimates the concentration of $\mathrm{ClO}_{\mathrm{x}}$ by $0.4 \%$ during the night-time, but this improves at the expense of overestimates of peak $\mathrm{ClO}_{\mathrm{x}}$ of $1.5 \%$ during the day and $0.5 \%$ of $\mathrm{ClONO}_{2}$ by the end of the run. The initial discrepancy in $\mathrm{ClO}_{\mathrm{x}}$ is almost entirely due to a difference in $\mathrm{Cl}_{2} \mathrm{O}_{2}$ which dominates over $\mathrm{ClO}$ during the night. Figure $1 \mathrm{~b}$ also shows that the relative error for $\mathrm{ClO}_{\mathrm{x}}$ and $\mathrm{ClONO}_{2}$ shows a slight increase for a short period around sunrise and sunset. At these times the photolysis rates are changing quickly and the VODE integrator better simulates the rapid changes in some species by using smaller time steps whereas IMPACT is a fixed time step method. Sandilands and McConnell (1997) modify their 
fixed step method around sunrise and sunset to use shorter time steps to overcome the inaccuracies of their method during these events. However, as Sandilands and McConnell (1997) point out, these inaccuracies during sunrise and sunset are often of little interest chemically and in practice usually do not warrant the use of a variable time step to improve the results during these times, particularly in global chemical simulations.

Figure $2 \mathrm{a}, \mathrm{b}$ shows the comparison between the IMPACT and VODE runs for OClO and some of the bromine species. Only the first two days are shown in order to expand the $\mathrm{x}$ axis and show the detail of the differences more clearly. The differences in the species shown are consistent throughout the duration of the run. Figure 3 shows that during the night-time, IMPACT overestimates the $\mathrm{OClO}$ by about $10 \%$ to $18 \%$ whereas the differences for $\mathrm{BrCl}$ and $\mathrm{BrO}_{\mathrm{x}}$ are considerably less. The night-time concentration of $\mathrm{OClO}$ is
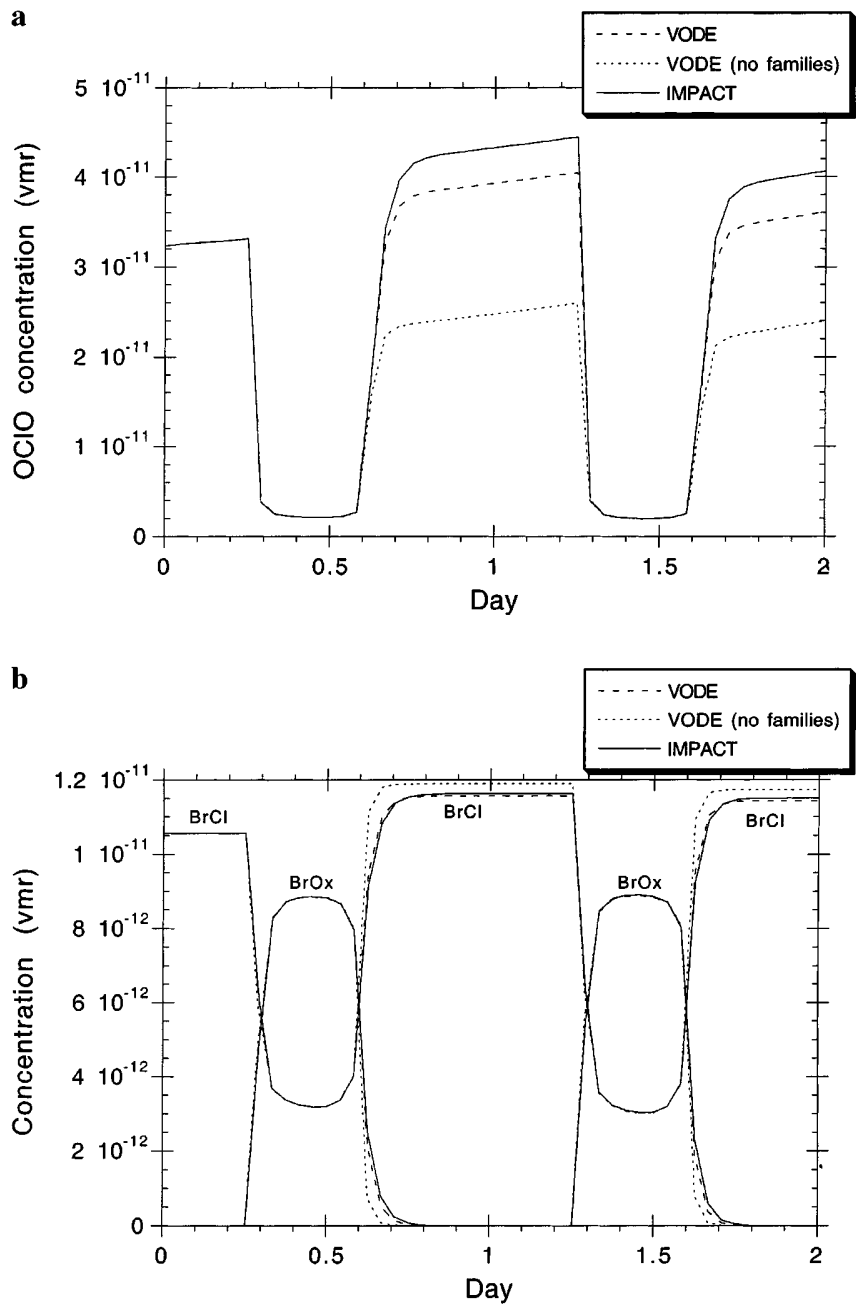

Fig. 2a,b. Comparison of results from a 6.5 day box model run using the IMPACT and VODE integrators for a OClO $\mathbf{b} \mathrm{BrO}_{\mathrm{x}}$ and $\mathrm{BrCl}$. Concentrations are in volume mixing ratio. Three curves are plotted for each species. The IMPACT integration is the solid curve. The long dashed curve is the VODE integration using chemical families, whereas the dotted curve is the VODE integration in which no chemical families or steady state species are used. Only the first two days of the run are shown for clarity

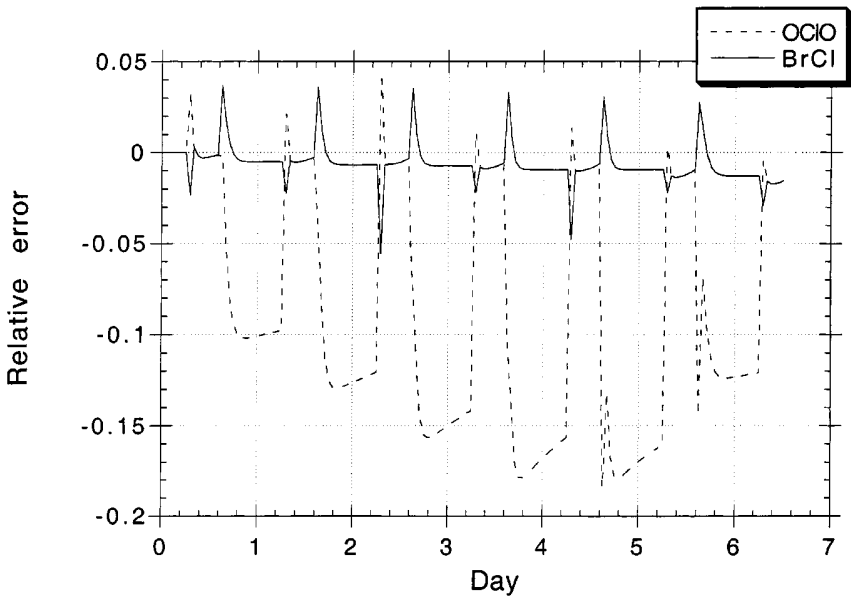

Fig. 3. Relative error for $\mathrm{OClO}$ and $\mathrm{BrCl}$ defined as (VODEIMPACT)/VODE where the VODE run with families is used (long dashed curve in Figs. 1 and 2). Dashed curve is $\mathrm{OClO}$ and solid curve is $\mathrm{BrCl}$

very sensitive to the amount of $\mathrm{BrO}$ and $\mathrm{ClO}$ at twilight, via the reactions

$\mathrm{BrO}+\mathrm{ClO}=\mathrm{OClO}+\mathrm{Br}$
$\mathrm{BrO}+\mathrm{ClO}=\mathrm{BrCl}+\mathrm{O}_{2}$.

At twilight, the IMPACT scheme overestimates the concentration of $\mathrm{BrO}$ but $\mathrm{ClO}$ is virtually the same in both runs. Hence the production of $\mathrm{OClO}$ increases to give more night-time $\mathrm{OClO}$ until the bromine is tied up in the reservoir species $\mathrm{BrCl}$. Figure 3 shows the relative error with peaks at sunrise and sunset as in Fig. 1b. the difference in $\mathrm{OClO}$ is the largest error of all the species in the model for this particular case.

Another test was carried out in which the VODE integrator was again used but without any families or species assumed to be in steady state. All chemical species (except those assumed to be constant) were integrated separately. Since IMPACT is designed for use with chemical families (in order to reduce the overall stiffness of the system), it is important to verify that a family based chemistry compares well with the more accurate case when no families or steady-state assumptions have been made. Figure 1a shows the difference between the IMPACT run and VODE run without families or species held in steady-state (hereafter referred to as the non-family run). The results are generally the same as the VODE run with families, the most noticeable difference is that the non- family VODE integration has more $\mathrm{ClO}_{\mathrm{x}}$ than the other two runs in Fig. 1a. As before this difference is mostly due to difference in the concentration of $\mathrm{Cl}_{2} \mathrm{O}_{2}$. The relative errors for these species (not shown) is very similar to Fig. $1 \mathrm{~b}$ but with greater magnitude. There is a $2 \%$ error in the $\mathrm{ClO}_{x}$ concentration initially during night-time, which by the end of the run has become a $-2 \%$ error during the day and $1 \%$ during the night. The relative errors in $\mathrm{HCl}$ and $\mathrm{ClONO}_{2}$ at the end of the run are $-0.2 \%$ and $0.6 \%$ respectively.

Figure 2a, $\mathrm{b}$ shows the differences between IMPACT and the non-family VODE runs for $\mathrm{OClO}$, 
$\mathrm{BrO}_{\mathrm{x}}$ and $\mathrm{BrCl}$. As for the chlorine species, the comparison is generally good but the magnitude of the errors has increased. Again, the largest errors are around twilight. The non-family VODE run now removes $\mathrm{BrO}$ much faster, forming the $\mathrm{BrCl}$ more quickly resulting in less night-time $\mathrm{OClO}$ than in either of the family-based IMPACT or VODE runs shown in Fig. 2a, b. During the night, IMPACT is overestimating $\mathrm{OClO}$ by a factor of two; which for this chemical scenario has been shown to be mostly a result of the use of chemical families and not errors from the time scheme.

\subsection{Runs of 100 days}

It is important to verify the IMPACT integrator over much longer runs in order to test various properties of the scheme, such as its conservation and errors in longer lived species. It is also important to test the likely errors associated with various diagnostics that might be computed. In the contest of this stratospheric chemistry scheme one such diagnostic would be the loss of ozone over a long time period.

An idealized scenario, designed to simulate the chemistry of the arctic lower stratosphere during a winter, was used as described in Chipperfield (1993). It consists of an idealized trajectory at a fixed altitude (50 $\mathrm{hPa})$, latitude and longitude $\left(65^{\circ} \mathrm{N}, 0^{\circ} \mathrm{E}\right)$. The trajectory starts on November 26th and runs for 100 days. The temperature is fixed at $210 \mathrm{~K}$ except for two PSC 'events' (between days 19 and 25 and days 54 and 64) when the temperature is reduced to $192 \mathrm{~K}$. This scenario was used for the EEC-funded STEP program for comparing chemistry schemes from different modelling groups. The same box model and chemistry is used as described already. Two runs were carried out; one with the IMPACT integrator, the other using the VODE integrator with families.

For the chemistry scheme used in this model, the total chlorine $\left(\mathrm{Cl}_{\mathrm{y}}=\mathrm{ClO}_{\mathrm{x}}+\mathrm{OClO}+\mathrm{HOCl}+\mathrm{HCl}+\right.$ $\left.\mathrm{ClONO}_{2}+\mathrm{BrCl}\right)$ and total bromine $\left(\mathrm{Br}_{\mathrm{y}}=\mathrm{BrO}_{\mathrm{x}}+\right.$ $\mathrm{BrCl}+\mathrm{BrONO}_{2}+\mathrm{HBr}+\mathrm{HOBr}$ ) should be perfectly conserved. As the Euler backward method (Eq. 3) on which IMPACT is based is conservative, IMPACT will conserve as long as the ratios are computed in a consistent manner and the method is allowed to take as many iterations as necessary for convergence. For this 100 days test case, the total chlorine and bromine are conserved to five significant figures which is consistent with the tolerances used in the model.

To verify the IMPACT scheme over long time periods for longer lived species, in the context of this scenario, the differences in ozone are appropriate. Figure 4 shows the ozone concentration from the VODE run. Also shown is the relative error between the ozone from the VODE and IMPACT runs. The sharp decreases in ozone around days 19 and 54 are due to the onset of PSC events, when the stiffness of the equations increases as some species are rapidly destroyed due to the PSC reactions. The relative error for

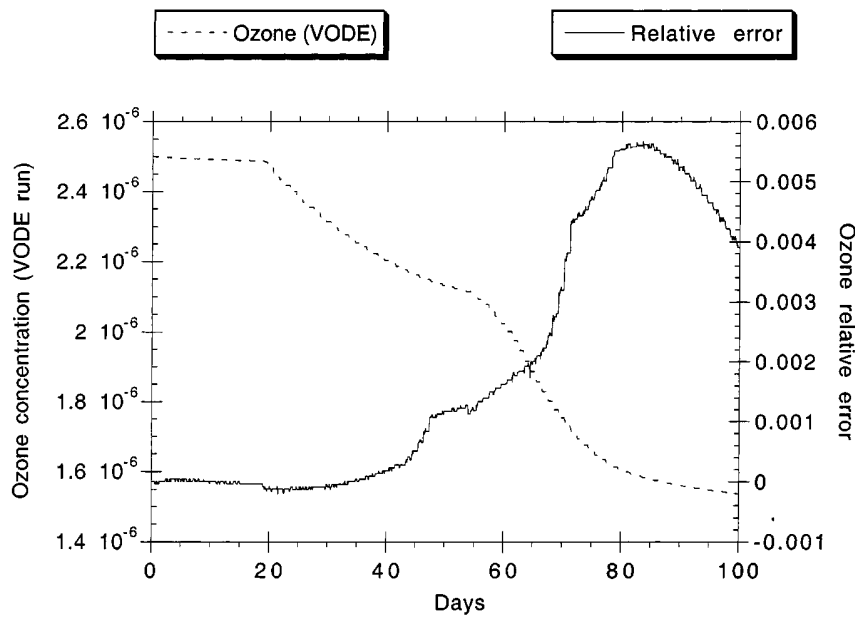

Fig. 4. Comparison of the $\mathrm{O}_{3}$ from 100 day runs of the box model for the IMPACT and VODE integrators. The ozone concentration from the VODE integrator is shown as the dashed curve on the left $y$ axis. The right $y$ axis shows the relative error between the two integrators, defined as (VODE-IMPACT)/VODE

ozone though is very small; reaching at most $0.5 \%$ during the 100 days.

It is important to know what effect the use of different integrators might have on the calculation of diagnostics such as the ozone budget. To ascertain this, for this particular case, the most important reactions for production and loss of odd oxygen are considered (reactions which result in merely an interchange of species within the odd oxygen family are ignored). Figure 5 shows the mean production and loss rates for key reactions averaged over the entire 100 days. The figure shows very good agreement between the VODE and IMPACT runs. The relative error for these reactions is also shown in Fig. 5. The largest difference of $1.9 \%$ is for $\mathrm{Br}+\mathrm{O}_{3}$ but this makes a small contribution to the odd oxygen budget. Of the other reactions, the relative

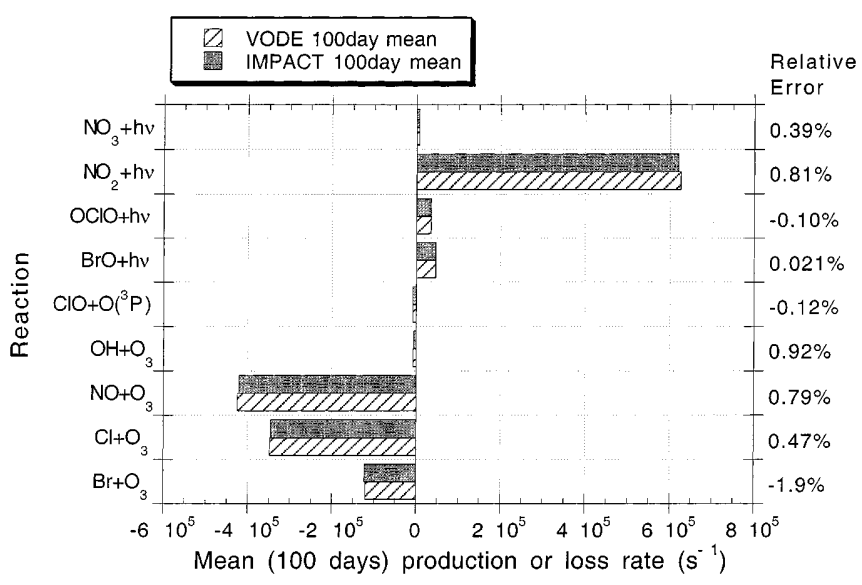

Fig. 5. This shows the mean over 100 days of the production or loss rate of the reactions that contribute the most to the change in odd oxygen for this box model. The results from the runs using the VODE and IMPACT integrators are shown. To the right of the graph the relative error between the two integrators is listed. The relative error is defined as (VODE-IMPACT)/VODE 
error is less than $1 \%$ which augurs well for the use of the IMPACT scheme in stratospheric chemistry simulations and budget calculations.

\section{Discussion}

It is customary in literature presenting new time integration methods to compare CPU timings of the new method with a benchmark integrator such as VODE, and we present some in this section. In general however, the value of such comparisons is limited because they are dependent on the local computing environment, the chemistry scenario (for iterative methods), to some extent the skill of the programmer and sometimes the computer architectures used.

For the 100 day runs presented in the preceding section the IMPACT method is faster than VODE by a ratio of 5:1, when tested on a cache based microprocessor (Sun Ultra) Unix workstation, using a specified relative tolerance of $10^{-5}$. The VODE integrator computes its own internal Jacobian via finite differences. However, since IMPACT and VODE are both iterative methods this ratio will be dependent on the chemistry scenario being used. For example, for the short 6.5 day runs presented the ratio of CPU time of IMPACT to VODE is $7.5: 1$. The reason for this difference is that there were no PSC events in this shorter run: these can significantly alter the stiffness of the equations to be solved and hence the number of iterations.

The iterations required by the corrector step of the IMPACT scheme vary significantly during the run. Figure 6 shows the number of iterations required for the 100 day run described. During the night, when many reactions are effectively turned off the scheme only requires at most two or three iterations; sometimes four and occasionally only one. However, during the day the number of iterations required for convergence changes depending on the circumstances. For instance, Fig. 6 shows how the number of iterations increases when the temperature decreases and PSCs form (at day 19) and

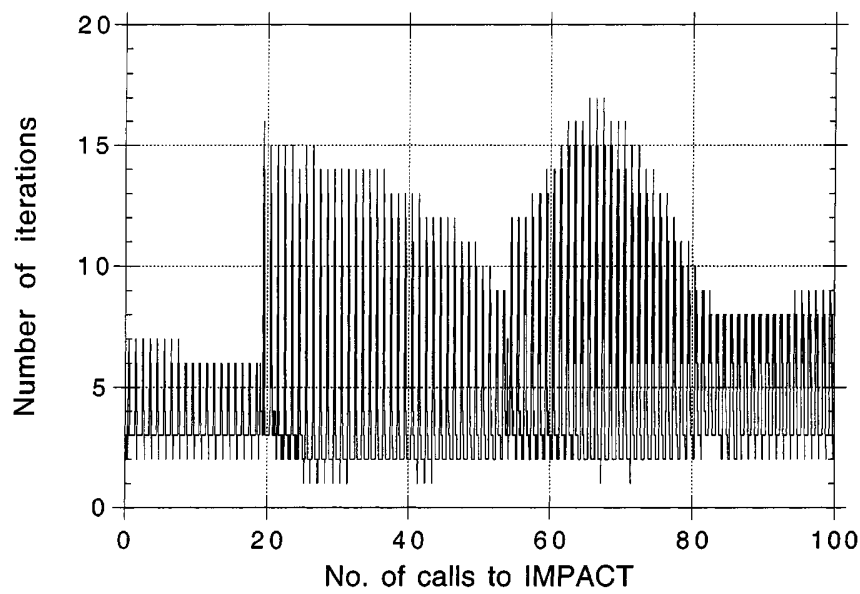

Fig. 6. Number of iterations required by the corrector step for each call to the IMPACT subroutine for the 100 day box model run. A 15 min time step was used then gradually decreases as the species return to their unperturbed concentrations.

The number of iterations required also depends on the time step chosen. Figure 6 shows the number of iterations for a $15 \mathrm{~min}$ time step. If a time step of $30 \mathrm{~min}$ is chosen the number of iterations required during the day is just less than double (the maximum iterations required increases by a factor of 1.7) and this is found for both the 6.5 and 100 day runs discussed. However, during the night, the number of iterations required remains low. Using a $30 \mathrm{~min}$ time step instead of a 15 min time step results in the box model running $30 \%$ faster.

Since IMPACT is unconditionally stable if the corrector iteration converges then increasing the time step acts to reduce the accuracy of the results. For example, at the end of the 100 day run, the ozone concentration for runs of 15 and $30 \mathrm{~min}$ were different by $0.4 \%$ and $1.0 \%$ respectively when compared with the VODE run. A time step of 60 min was unsuitable for this case. For shorter lived species, the difference is more pronounced. As an example Fig. 7 shows the difference between runs for $\mathrm{HBr}$.

Figure 8 illustrates the efficiency of the IMPACT scheme as a function of the specified relative tolerance, similar to the 'work efficiency' diagrams of Sandu et al. (1997a). This gives the user an idea of the performance of the method in relation to its input parameters. IMPACT is clearly efficient since increased accuracy can be obtained for modest increases in computer time. The VODE integrator shows a larger increase in CPU time for increased precision. Sandu et al. (1997a) developed a modified VODE integrator in which they use a custom sparse matrix package to improve the efficiency of the VODE integrator, however VODE is used for these tests with no alterations to its code. For the integrations presented here, a minimum relative tolerance of $10^{-3}$ is required before acceptable results are obtained.

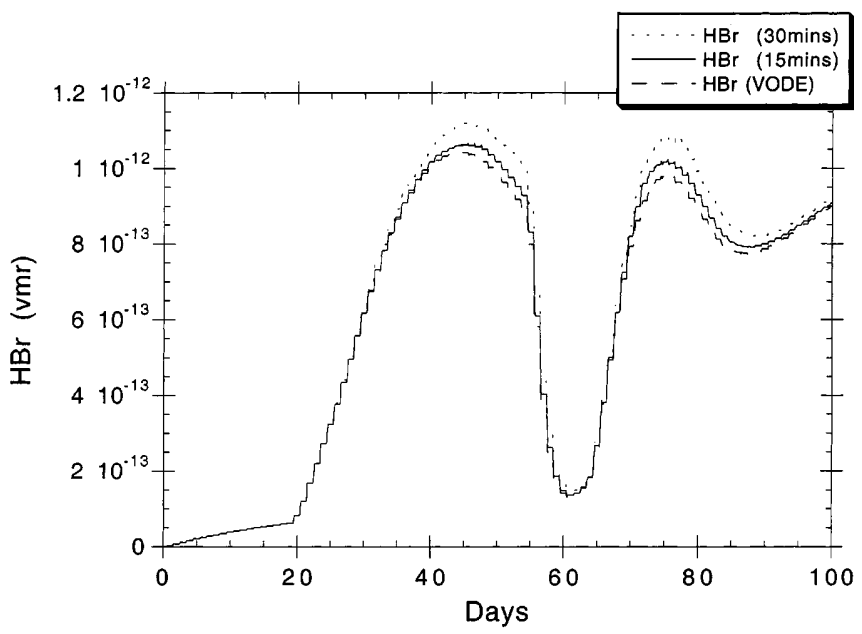

Fig. 7. The difference between the concentration of a short-lived species, $\mathrm{HBr}$, for the VODE run (long dashed curve), IMPACT with a 15 min time step (solid curve) and 30 min time step (short dashed curve) 


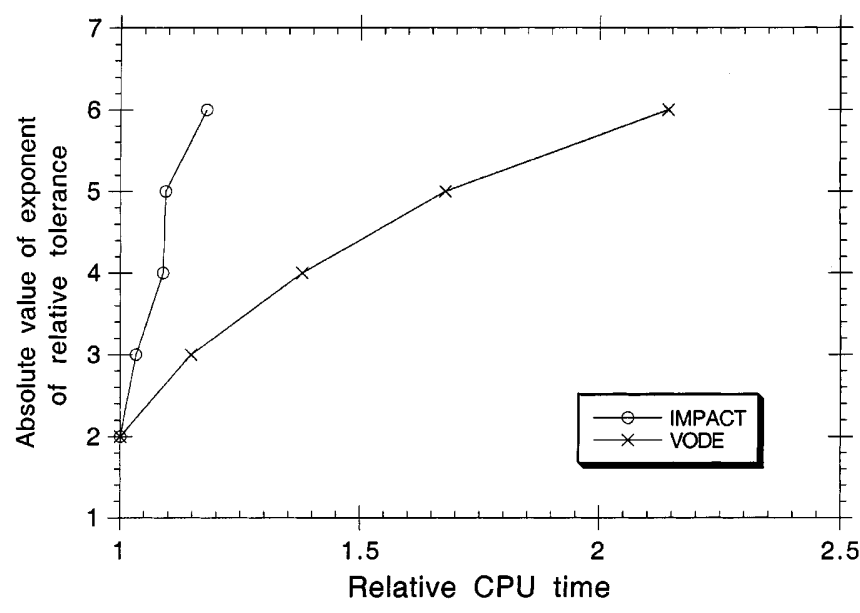

Fig. 8. This shows the efficiency of the integrators as precision requirements are increased. The y-axis is the absolute value of the exponent of the relative tolerance set in the integrator. For example $y=2$ means that a relative tolerance of $10^{-2}$ was used. The $x$-axis is the CPU time required by the integrator at each relative tolerance but scaled so that the curves for the integrators start at the same point. The CPU times for each integrator are scaled by dividing each CPU time measured by the time for the $y=2$ case respectively

Variations on the method presented here have been tested. By inverting the full Jacobian matrix only in the predictor step the initial guess for the Newton iteration is improved and the number of iterations used reduced. However, this is offset by the increased cost for inverting the matrix which makes this approach more expensive. There are also more sophisticated alternatives to the Newton-Raphson iteration scheme used in IMPACT and one such scheme is the globally convergent variation of Newton's method, with line searching and back tracking, as described in Sect. 9.7 of Press et al. (1992). If this is implemented in the corrector iteration with all the terms in the matrix $\mathbf{A}$ retained, again the number of iterations is reduced but the scheme is much more expensive than IMPACT. Once again there is no gain in accuracy over IMPACT even though the iteration method is more sophisticated.

\section{Summary}

A modified and improved version of the fixed step implicit time integration method for atmospheric chemical modelling, first proposed by Stott and Harwood (1993) has been presented and named IMPACT. The original method had some stability problems when tried for chemical schemes typically used for stratospheric ozone depletion studies and more complex than presented in SH93. The IMPACT scheme incorporates the improvements to the SH93 scheme that have been outlined in this study; the recalculation of the family ratios for the first corrector iteration, amendment of the predictor step when the main diagonal Jacobian matrix elements are positive, incorporation of the additional matrix elements from the photolysis reactions for the corrector iteration when the Newton-Raphson method is not converging.
The method has been shown to be conservative, robust and produce results that compare well with a higher order variable step method (VODE), for cases typical of stratospheric ozone depletion studies in which heterogeneous reactions on polar stratospheric clouds occur. The method is computationally inexpensive, straightforward to implement and produces efficient vectorized code on appropriate computer architectures. The scheme has been implemented in our 3D chemical transport model and used for both stratospheric and tropospheric chemistry studies without any problems.

Acknowledgements. This work was funded by the Natural Environment Research Council under the UK Universities Global Atmospheric Modelling Programme. We are grateful to Dr. R. S. Harwood for suggesting the binomial expansion. We thank Dr. Paul Brown and Dr. Martyn Chipperfield for many helpful discussions. We also thank Dr. David Lary for the use of his photolysis scheme and Peter Good for the use of his heterogeneous chemistry scheme. We also thank the anonymous referees for their useful comments. The Centre for Atmospheric Science is a joint venture between the Departments of Chemistry and Applied Mathematics and Theoretical Physics in the University of Cambridge.

Topical Editor F. Vial thanks C. Kessler and another referee for their help in evaluating this paper.

\section{References}

Anderson, D. E., The troposphere to stratosphere radiation field at twilight: a spherical model, Planet. Space Sci., 31(12), 1517$1523,1983$.

Austin, J., On the explicit versus family solution of the fully diurnal photochemical equations of the stratosphere, J. Geophys. Res., 96, 12 941-12 974, 1991.

Brown, P. N., G. D. Byrne, and A. C. Hindmarsh, VODE: a variable coefficient ODE solver, SIAM J. Sci. Stat. Comput., 10, 10381051, 1989.

Carver, G. D., P. D. Brown, and O. Wild, The ASAD atmospheric chemistry integration package and chemical reaction database, Comp. Physics. Comm., 105, 197-215, 1997.

Chipperfield, M. P., Intercomparison of stratospheric chemistry schemes of three-dimensional models, UGAMP Technical Report 34, UK Universities Global Atmospheric Modelling Programme, Unpublished, copies available from Meteorology Department, Reading University, UK, December 1993.

Chipperfield, M. P., M. L. Santee, L. Froidevaux, G. L. Maney, W. G. Read, J. W. Waters, A. E. Roche, and J. M. Russell, Analysis of UARS data in the southern polar vortex in September 1992 using a chemical transport model, J. Geophys. Res., 101, 18 861-18 881, 1996.

Dabdub, D., and J. H. Seinfeld, Extrapolation technique used in the solution of stiff ODEs associated with chemical kinetics of air quality models, Atmos. Environ., 29, 403-410, 1995.

Gear, C. W., Numerical initial value problems in ordinary differential equations, Prentice Hall, Englewood Cliffs, New Jersey, 1971.

Hairer, E., and G. Wanner, Solving ordinary differential equations II. Stiff and differential algebraic problems, Springer, Berlin Heidelberg New York, 1996.

Jacobson, M. Z., Computation of global photochemistry with SMVGEAR II, Atmos. Environ., 29, 2541-2546, 1995.

Jacobson, M. Z., and R. P. Turco, SMVGEAR: a sparse-matrix, vectorized GEAR code for atmospheric models, Atmos. Environ, 28, 273-284, 1994.

Lary, D. J., and J. A. Pyle, Diffuse radiation, twilight and photochemistry-I, J. Atmos. Chem., 13, 373-392, 1992 a. 
Lary, D. J., and J. A. Pyle, Diffuse radiation, twilight and photochemistry-II, J. Atmos. Chem., 13, 393-406, 1992b.

Lary, D. J., J. A. Pyle, and G. D. Carver, A 3-dimensional model study of nitrogen-oxides in the stratosphere, Q.J. R. Meteorol. Soc., 120, 453-482, 1994.

Law, K. S., P. H. Plantevin, D. E. Shallcross, H. L. Rogers, J. A. Pyle, C. Grouhel, V. Thouret, and A. Marenco, Evaluation of modeled $\mathrm{O}_{3}$ using measurement of ozone by airbus in-service aircraft (MOZAIC) data, J. Geophys. Res., 103, 25 721-25 741, 1998.

Meier, R. R., D. E. Anderson, and M. Nicolet, The radiation field in the troposphere and stratosphere from $240 \mathrm{~nm}$ to $1000 \mathrm{~nm}$ : general analysis, Planet. Space Sci., 30(9), 923-933, 1982.

Mesinger, F., and A. Arakawa, Numerical methods used in atmospheric models, vol I, Global Atmospheric Research Program Publications Series, WMO-ICSU Joint Organizing Committee, 1976.

Nicolet, M., R. R. Meier, and D. E. Anderson, The radiation field in the troposphere and stratosphere from $240 \mathrm{~nm}$ to $1000 \mathrm{~nm}$. numerical analysis, Planet. Space Sci., 30(9), 935-983, 1982.

Press, W. H., S. A. Teukolsky, W. T. Vetterling, and B. P. Flannery, Numerical recipes in Fortran, 2nd edn, Cambridge University Press, Cambridge UK 1992.

Radhakrishnan, K., Combustion kinetics and sensitivity analysis computations, in Numerical approaches to combustion modelling, Eds., E. S. Oran, and J. P. Boris, Progress in astronautics and aeronautics, 135, 83-128, 1991.

Ramaroson, R. A., M. Pirre, and D. Cariolle, A box model for online computations of diurnal variations in a 1-D model: potential for application in multidimensional cases, Ann. Geophysicae, 10, 416-428, 1992.
Rose, K., and G. A. Brasseur, A three-dimensional model of chemically active trace species in the middle atmosphere during disturbed winter conditions, J. Geophys. Res., 94, $16387-$ 16 403, 1989.

Sandilands, J. W., and J. C. McConnell, Evaluation of a reduced Jacobian chemical solver, J. Geophys. Res., 102, 19 073-19 087, 1997.

Sandu, A., J. G. Verwer, M. van Loon, G. R. Carmichael, F. A. Potra, D. Dabdub, and J. H. Seinfeld, Benchmarking stiff ODE solvers for atmospheric chemistry problems I: implicit versus explicit, Atmos. Environ., 31, 3151-3166, 1997a.

Sandu, A., J. G. Verwer, J. G. Blom, E. J. Spee, and G. R. Carmichael, Benchmarking stiff ODE solvers for atmospheric chemistry problems II: Rosenbrock solvers, Atmos. Environ., 31, 3459-3472, 1997b.

Sillman, S., A numerical solution for the equations of tropospheric chemistry based on an analysis of sources and sinks of odd hydrogen, J. Geophys. Res., 96, 20 735-20 744, 1991.

Stott, P. A., and R. S. Harwood, An implicit time-stepping scheme for chemical species in a global atmospheric circulation model, Ann. Geophysicae, 11, 377-388, 1993.

Suhre, K., and R. Rosset, Modification of a linearized semi-implicit scheme for chemical reactions using a steady-state-approximation, Ann. Geophysicae, 12, 359-361, 1994.

Verwer, J. G., and D. Simpson, Explicit methods for stiff ODEs from atmospheric chemistry, Appl. Num. Math., 18, 413-430, 1995.

World Meteorological Organisation, Scientific assessment of ozone depletion: 1991, WMO, Global ozone research and monitoring project, Rep 25, 1991. 